\title{
Aplicabilidades do sensoriamento remoto no ensino de geografia
}

\author{
Cibele Stefanno Saldanha, Marcia Elena de Mello Cardias, Mauro Kumpfer Werlang
}

https://doi.org/10.4322/mp.978-65-991393-8-3.c7

\section{Resumo}

A terminologia sensoriamento está frequentemente correlacionada ao processo de aquisição de dados ou informações sobre algo, um objeto ou entidade. O termo remoto por sua vez, transmite a ideia de algo feito à distância, sem que haja contato direto com o objeto. As constantes transformações tecnológicas impõem aos educadores novos ritmos e perspectivas na forma de ensinar e aprender. Assim é necessário que o educador se mantenha em permanente estado de aprendizagem e adaptações. Na educação, a utilização de geotecnologias auxilia os educandos a participarem e construírem seus conhecimentos. Dessa forma, desenvolve-se neles o senso reflexivo e crítico, pois estudarão sobre o contexto no qual estão inseridos na sociedade. O uso das geotecnologias provenientes do sensoriamento remoto, quando utilizadas como recursos didáticos em salas de aula, apresentam contribuições significativas para o processo de ensino e aprendizagem. Ao partir do pressuposto da conjectura de que, embora o uso de imagens de satélites e fotografias aéreas sejam frequentemente utilizadas pelos meios de comunicações e, que essas ilustram e exemplificam diversos conteúdos, são raros os educadores que exploram todo o potencial do sensoriamento remoto e suas atribuições. Nesse sentido, suscita-se como problema a falta de aptidão e despreparo por parte de alguns educadores acerca da utilização e dos meios de ensinar o sensoriamento remoto. Diante do exposto têm-se como objetivo apresentar as diversas aplicabilidades e práticas cotidianas do sensoriamento remoto no âmbito escolar. Para isso, busca-se apresentar os meios e técnicas que foram eficazes na utilização do sensoriamento remoto em sala de aula. Para tal fim, foi realizado um levantamento bibliográfico de trabalhos que abordam os distintos gêneros de aplicações e benefícios que a técnica produziu e, portanto, sugere-se ser explorada pelos educadores em sala de aula. Mediante as investigações propostas nesta pesquisa, conclui-se que as imagens aéreas colaborem de forma significativa no processo de ensino e aprendizagem, desta forma, é indispensável que os educadores estejam capacitados e entusiasmados para desenvolver um bom trabalho, com o apoio das geotecnologias.

Palavras-chave: geografia escolar, geotecnologias; imagens de satélites.

\section{Introdução}

O avanço tecnológico especialmente no que tange o campo da informação e da comunicação tem provocado grandes impulsos no que diz respeito as transformações sociais, transformações que ocorrem cada vez mais rápidas. O resultado que esses avanços trazem estão relacionados ao aumento da capacidade de observação do espaço inserido em diversas escalas o que possibilita o monitoramento das 
modificações na superficie terrestre. Na educação as transformações não ocorrem na mesma intensidade da tecnología gerando assim distancias a serem recuperadas ao ensinar. A informática está cada dia mais presente na sala de aula, através de suas diversas plataformas que permitem o aprimoramento no processo de ensino e aprendizagem. Com isso ela é percebida pelos professores como um poderoso instrumento facilitador no ensino.

A Geografia compreende o sensoriamento remoto como uma tecnología que permite o desenvolvimento de estudos mais criteriosos e detalhados sobre a superficie terrestre. Conforme afirma Carvalho [1] a utilização de imagens de satélites e fotografías aéreas na educação básica configuram avanços consideráveis no que refere-se a qualidade de ensino principalmente na Geografia, através desta ferramenta é possível verificar a capacidade de dinamismo dos estudos e percepção do espaço geográfico, pois através deste é plausível sanar problemas que ocorrem no ensino da Geografia. Neste contexto, o cenário atual e as transformações tecnológicas colocam os professores em condições de aprimoramento em seus métodos de ensino e aprendizagem.

Este estudo justifica-se pela necessidade de difundir as imagens de satélites em sala de aula e atender as orientações que estão dispostas na Base Nacional Comum Curricular (BNCC), muitos livros didáticos ilustram e exemplificam diversos conteúdos curriculares através das imagens de satélite, entretanto, este recurso didático ainda é pouco explorado pelos educadores na escola. Segundo Kramer et al. [2] o uso de técnicas avançadas para a visualização do espaço geográfico, como imagens de satélites e fotografias aéreas, proporcionam uma nova forma de vislumbrar e compreender o espaço e, desta forma, é possível trabalhar diversos conteúdos como: geomorfologia, recursos hídricos, áreas urbanas, climatología, ensino de cartografia, vegetação dentre outros.

O presente estudo tem como objetivo expor a todos educadores as diversas aplicabilidades e práticas cotidianas do sensoriamento remoto no âmbito escolar, apontando os beneficios desta técnica no ensino quando bem utilizadas, sendo esta é acessível para qualquer professor que deseja desenvolver este trabalho. Para tal, busca-se difundir os meios e técnicas que foram eficazes na utilização do sensoriamento remoto em sala de aula, como sugestão de trabalhos que podem ser adaptados de acordo com a realidade de cada escola. Para tal fim, a metodología realizada foi investigativa através do levantamento bibliográfico de trabalhos que abordam os distintos gêneros de aplicações e benefícios que a técnica produziu, e portanto sugere-se ser explorada pelos educadores em sala de aula.

De acordo com Kramer et al. [2] há uma grande necessidade de utilizar-se a técnica de sensoriamento remoto nas escolas. Portanto, é preciso que os professores venham a trabalhar com conteúdos e recursos didáticos que qualifiquem os alunos para a vida na sociedade moderna e tecnológica. Nesse sentido, tanto a Lei 9394/96 de Diretrizes e Bases da Educação como os Parâmetros Curriculares Nacionais - PCNs propõem a inserção de novas tecnologias no processo ensino e aprendizagem. Segundo o MEC [3] considera que os novos Parâmetros Curriculares Nacionais reforçam a importância do uso do sensoriamento remoto como recurso educacional, sobretudo pela possibilidade de se extraírem informações espaciais.

\section{Desenvolvimento}

\subsection{Referencial Teórico}

\subsubsection{O uso das geotecnologias}


Segundo a Base Nacional Comum Curricular (BNCC) é oportuno a utilização das Tecnologias de Informação e Comunicação (TIC). Elas são instrumentos de mediação aliados do professor no proceso de ensino e aprendizagem nas escolas. Os professores em especial devem contribuir para que o estudante aprenda a obter, transmitir, analisar e selecionar informações [3] proporcionando um papel ativo ao estudante.

Para Masseto [4] as novas tecnologías apresentam-se com um instrumento que vem para colaborar no desenvolvimento da aprendizagem. Entretanto não é a tecnología que irá resolver ou solucionar o problema educacional do Brasil, contudo ela é uma ferramenta que poderá colaborar efetivamente se forem utilizadas adequadamente, para o desenvolvimento educacional de nossos estudantes.

De acordo com Lima [5], as TICs não combinam com velhos hábitos, entretanto é necessário 0 uso fundamentado nas perspectivas construtivistas ou sociointeracionistas. Desta forma, busca-se uma aprendizagem ativa, na qual o aluno interaja com os recursos tecnológicos, mas que, além disso, seja um aluno crítico capaz de construir conceitos e compartilhar conhecimentos com seus colegas, através do diálogo.

Os recursos tecnológicos de forma geral, associados ao ensino não possuem a finalidade de reproduzir conteúdos ou técnicas, mas de proporcionar a realização de aulas mais criativas, motivadoras. Esta dinâmica envolve os alunos para as novas descobertas e aprendizagens [6]. Segundo Masseto [4], através das TICs é possível formar um ambiente reflexivo e investigativo, tornando as aulas mais interativas e desafiadoras

As geotecnologias são reconhecidas por fazer parte do geoprocessamento, ou seja, fazem parte de um conjunto de técnicas na qual são coletadas, processadas, analisadas e colocadas à disposição como referência geográfica. A geotecnologia é o conceito desenvolvido através das tecnologias de informação, e é utilizada pela geografia, cartografia, topografia entre outras ciências que contemplam o estudo geográfico. Desta forma, as geoinformações são aquisições de materiais que farão parte de análise ou processamento, que nesta área, é chamada de informações georeferenciadas, com dados mais precisos e imagens em tempo real.

O uso das geotecnologias pode ser entendido como as novas tecnologias ligadas às geociências as quais trazem avanços significativos no desenvolvimento de pesquisas, em ações de planejamento, em processos de gestão e manejo e, em tantos outros aspectos relacionados à estrutura do espaço geográfico. Essas considerações tornamse importantes à medida que profissionais das mais diversas áreas atuam diretamente com as questões espaciais. Entretanto, a interatividade necessária para que se possa trabalhar o meio ambiente como um todo, de forma interdisciplinar, torna necessária uma busca por ferramentas e técnicas qualificadas para sua concretização. A inserção de profissionais de diferentes áreas do conhecimento, torna-se essencial para um bom resultado dos trabalhos desenvolvidos [7].

O Sistema de Informação Geográfica (SIG), é utilizado no planejamento e execução de estudos e atividades fundamentais na geografia, tendo a função de captura, armazenamento, visualização, manipulação, interpretação e exportação de dados geográficos a fim de viabilizar a correta gestão dos recursos naturais. Para as geotecnologias, ter seu aproveitamento efetivo é fundamental obter boas fontes de dados, assim como um bom entendimento do problema que será desenvolvido, de forma a conceber análises que forneçam resultados mais expressivos. Além disso, é imprescindível haver o domínio acerca da informática, sensoriamento remoto, 
geomática e geografia. O avanço tecnológico proporciona a integração de dados em um ambiente computadorizado intitulado como Sistema de Informação Geográfica, que propicia a reprodução de feições e fenômenos terrestres. Além disso, é possível analisar e interpretar um objetivo específico utilizando as infinidades de dados dos sensores remotos, bases cartográficas e diversos softwares [8].

\subsubsection{O Ensino em geografia}

Atualmente a geografia enfrenta inúmeros desafios, esses, são distintos e muito mais complexos dos que já se apresentaram durante a sua extensa trajetória. A indagação que vem sendo discutida nas últimas décadas é sabermos se ela está em condições de responder a esses desafios. Além disso, a geografia é uma das ciencias determinantes capazes de apontar o rumo que a humanidade está caminhando para 0 seu crescimento, pois, "pensando criticamente a prática de hoje ou de ontem que se pode melhorar a próxima prática" [9].

As inter-relações que ocorrem entre a educação, escola e sociedade tornam-se objetos de transformação contínua, que influenciam o modelo educacional vigente, e a relação escola/sociedade. Desta forma, o professor representa a peça chave de todo processo, sendo mediador entre o conhecimento e o ser humano, assim como na contribuição da formação de valores morais e éticos. Para Pontuschka et al. [10] a geografia, como disciplina escolar, tem seu papel fundamentado na contribuição para alunos e profesores, com o objetivo de enriquecer suas representações sociais e seu conhecimento sobre as múltiplas dimensões da realidade social, natural e, seu processo contínuo nas transformações na paisagem. Sobretudo, no atual momento que é denominado "mundialização da economía".

Segundo Cavalcanti [11], o ensino escolar tornou-se um processo formado por componentes fundamentais e entre eles destaca-se os objetivos, os conteúdos e os métodos. Além disso, um dos maiores objetivos da escola, assim como o da geografia, é formar valores, ou seja, respeito ao próximo, respeito às diferenças, combate as desigualdade e às injustiças sociais. Cavalcanti [11] afirma ainda, que o ensino da geografia possui a finalidade de ação e transformação, de trabalhar o aluno juntamente com suas referências adquiridas na escola através das suas vivencias e sistematizá-las em contato com a sociedade e com o cotidiano para assim criar o pensar geográfico que leve em consideração as análises da natureza com a sociedade, como estas se relacionam e quais as dinâmicas resultantes deste processo.

O ensino de geografia pode levar os alunos a assimilação de forma ampla e vislumbrar a realidade do espaço vivido. Entretanto, é preciso que os alunos adquiram conhecimentos, dominem categorias, conceitos e procedimentos básicos com os quais este campo de conhecimento opera e constitui suas teorias e explicações, de modo a compreender as relações socioculturais e o funcionamento da natureza às quais historicamente pertence, além de conhecer e saber utilizar a forma singular no pensar geográfico sobre a realidade, ou seja, o conhecimento geográfico de fato [11].

Segundo os Parâmetros Curriculares Nacionais a geografia é a ciencia que possui um tratamento específico como área, uma vez que oferece instrumentos essenciais para compreensão e intervenção na realidade social. Por intermédio dela se pode entender como diferentes sociedades interagem no espaço geográfico com a natureza na construção deste espaço, e as singularidades do lugar em que vivemos, o que o diferencia e o aproxima de outros lugares e, assim, que estabelecemos com ele [12]. 
Para Santos [13] a problematização dos conteúdos é a palavra chave do pensar geográfico, quando o objetivo for a compreensão da realidade de forma ampla. A realidade deve ser problematizada a partir das vivências dos alunos, na busca da formulação de hipóteses que expliquem as relações e transformações da sociedade. Apartir dessa concepção conclui-se que o nível global e o nível local do acontecer são conjuntamente essenciais ao entendimento do mundo e do lugar. Mas o acontecer local é referido ao acontecer global.

\subsubsection{O Sensoriamento remoto na educação}

Atualmente as escolas estão relacionadas com a necessidade de acompanhar a evolução decorrente da introdução das tecnologias na sociedade. Do contrário, em vez de relacionar-se com o mundo em que vivemos, a escola tenderá a distanciar-se dele e poderá mesmo constituir um obstáculo ao desenvolvimento exigido por um meio em constante evolução [14]. Neste contexto, as geotecnologias se fundamentam como ferramentas imprescindíveis no proceso de ensino e aprendizagem em sala de aula.

Segundo Ferreira e Cunha [15], a informática está cada dia mais inserida nas escolas, seja pela internet, multimídia, seja pela utilização de novas tecnologias. Essas consistem no aproveitamento do processo da aprendizagem e, tem sido indicada como uma ferramenta fundamental e facilitadora do trabalho dos professores, em especial dos professores de Geografia. Neste sentido, o uso da Informática vem contribuindo com os professores na tarefa de transmitir o conhecimento e adquirir novas formas de ensinar cada vez mais criativas e dinâmicas, auxiliando novas descobertas e investigações [16].

O sensoriamento remoto tem potencial para ser um instrumento de grande importância para a aprendizagem ao utilizar as tecnologias dentro dos aspectos educacionais. Neste sentido, torna-se ferramenta imprescindível nas aulas de geografia para que os alunos possam conhecer adequadamente o local em que ele está inserido, isto é a sua casa, rua, cidade e estado. Desta forma, utilizar as tecnologías nas escolas facilita a compreensão do espaço geográfico e das relações físicas e socioeconômicas. Entretanto, faltam materiais didáticos sobre esta temática abordada no que diz respeito as geotecnologias, especialmente no que tange ao sensoriamento remoto na educação básica. É evidente a necessidade de disponibilizar material didático neste ramo científico para uma melhor compreensão da geografia [17].

Florenzano [17] afirma ainda que, a aplicação do sensoriamento remoto e do sistema de informações geográficas (SIG) intensificou-se nas últimas décadas, voltada as análises ambientais e urbanas, se tornando um método frequente em diversas áreas de pesquisas. Em conformidade, com Santos [18] a técnica de sensoriamento remoto propicia a leitura integrada do espaço geográfico, uma vez que sendo utilizado nos conteúdos de geografia e aplicado como recurso didático pedagógico para a compreensão do processo de uso e ocupação dos espaços, favorece a compreensão e o entendimento das inter-relações entre as questões sociais, econômicas, políticas e culturais, as quais configuram e constroem o espaço, salientando o avanço na repercussão em diferentes períodos. Proporciona o desenvolvimento de trabalhos de campo com o uso de mapas, fotos aéreas e imagens de satélite aspirando a compreensão das questões ambientais e sócio ambientais em diversas escalas.

A Lei de Diretrizes de Bases da Educação - LDB e os Parâmetros Curriculares Nacionais - PCNs fortalecem a relevância das novas tecnologias, a exemplo do sensoriamento remoto, sendo essas um recurso educacional que está a disposição dos professores. As imagens obtidas pelos sensores remotos destacam-se pela possibilidade de extrair informações 
multidisciplinares, pois nela consta dados, em uma única imagem, que podem ser empregados com diversas finalidades.

O sensoriamento remoto no ensino em geografia é utilizado a partir da análise e interpretação de imagens na qual podem ser trabalhados os seguintes conceitos: 0 espaço geográfico, o lugar, a localização, a interação entre o homem e o meio, a paisagem e o território, além de abrir possibilidades de realizar trabalhos em diferentes escalas. Conforme Vilhena et al.[19], os sensores remotos são excelentes ferramentas com alta potencialidade para serem utilizados como recurso didático no ensino em geografía. Destaca-se que esta ferramenta auxilia o professor a aproximar a realidade local e espacial. Para Santos [20] o sensoriamento remoto dispõe de diversas vantagens quando utilizado em sala de aula, pela sua abrangência espacial na qual garante a compreensão dos alunos do local abordado através das imagens, trazendo o espaço vivido mais próximo deles. Segundo Borges [21] ao empregar as imagens com ênfase nos aspectos temporais é possível analisar as transformações do espaço de forma investigativa e crítica. Através dos produtos dos sensores remotos (imagens de satélites) há oferta de uma gama de variáveis a serem estudadas.

\section{Metodologia}

O presente estudo é de cunho investigativo e bibliográfico. Para isso, foi proposto um levantamento bibliográfico de metodologias já desenvolvidas em outros trabalhos. Possui o propósito de sugerir práticas e aplicabilidades do sensoriamento remoto no ensino da geografia, visando facilitar o trabalho do professor de geografia quando da abordagem de conteúdos em sala de aula.

Desta forma, a primeira ação foi acessar os projetos sugeridos pelo Instituto Nacional de Pesquisa e Espaciais. A segunda pretendeu abordar a questão do lugar vinculado ao espaço geográfico. A terceira procurou demonstrar como o sensoriamento remoto pode auxiliar no ensino da disciplina de geografia. A quarta esteve relacionada a sugestão de desenvolvimento de atividades com imagens de satélites e, a quinta esteve vinculada às questões ambientais. $O$ quadro 1 ilustra essas etapas metodológicas.

Quadro 1. Descrição das ações metodológicas.

\begin{tabular}{|l|l|}
\hline \multicolumn{2}{|c|}{ METODOLOGIAS } \\
$\begin{array}{l}\text { 1- Projetos do Instituto } \\
\text { Nacional de } \\
\text { Espaciais/INPE } \\
\text { Pesquisas }\end{array}$ & $\begin{array}{l}\text { Desta ação metodológiçÃO o professor deve } \\
\text { acessar ao site criado pelo INPE, que possui o } \\
\text { projeto EducaSere. Este projeto é composto } \\
\text { por várias ferramentas que podem auxiliar os } \\
\text { alunos em sala de aula. }\end{array}$ \\
\hline 2- Estudo do lugar & $\begin{array}{l}\text { Esta ação metodológica propõe etapas de } \\
\text { ensino: Primeiramente inicia com os mapas } \\
\text { mentais, através dos desenhos, } \\
\text { posteriormente serão apresentadas imagens } \\
\text { de satélites. }\end{array}$ \\
\hline $\begin{array}{l}\text { 3- Sensoriamento Remoto no no } \\
\text { ensino de geomorfologia }\end{array}$ & $\begin{array}{l}\text { Esta atividade está vinculada com o ensino de } \\
\text { geomorfologia. A plataforma utilizada será o } \\
\text { Google Earth. }\end{array}$ \\
\hline
\end{tabular}




\begin{tabular}{|l|l|}
\hline 4- Imagens de satélites & $\begin{array}{l}\text { Para realizar esta atividade deve selecionar } \\
\text { imagens de satélites proveniente do programa } \\
\text { Google Earth das proximidades da escola, } \\
\text { com a finalidade de familiarizar os educandos } \\
\text { com o espaço vivido. }\end{array}$ \\
\hline $\begin{array}{l}\text { 5- Metodologia vinculada a a a a metodológica é } \\
\text { questões ambientais }\end{array}$ & $\begin{array}{l}\text { Para realizar esta ação mén de satélites de } \\
\text { necessário selecionar imagens de } \\
\text { locais identificados como áreas de risco. }\end{array}$ \\
\hline
\end{tabular}

Cabe salientar que as ações metodológicas que foram indicadas no quadro 1, apresentam-se como propósito de sugerir práticas e aplicabilidades do sensoriamento remoto no ensino da geografia, no intuito de apenas facilitar o trabalho do professor de geografia quando da abordagem de diferentes conteúdos em sala de aula.

\section{Resultados}

\subsection{Projetos do Instituto Nacional de Pesquisa Espaciais}

A aplicação dos dados do sensoriamento remoto no ensino de geografia ainda é recente. Entretanto tem gerado experiências com muito êxito. Neste sentido, o Instituto Nacional de Pesquisas Espaciais (INPE), possui projetos ligados a Divisão de Sensoriamento Remoto - DSR. Um deles é chamado de Programa Educa SeRe. Este programa foi criado pelo INPE em 1998 e tem como objetivo principal o desenvolvimento de material didático. Usa dados de sensoriamento remoto e técnicas de geoprocessamento para ensinar geografia e ciências naturais no ensino fundamental e médio. Esta metodologia está adaptada por Sausen e Coelho [22].

Os objetivos do Programa Educa SeRe é disponibilizar, com baixo custo para a comunidade em geral, dados de sensoriamento remoto dedicado à área de recursos naturais e difundir o uso de dados de sensoriamento remoto como recurso didático, nas disciplinas de ciência e geografia, tornando acessível os materiais didáticos para o ensino de sensoriamento remoto e de recursos naturais. Este projeto apresenta ferramentas que podem auxiliar no desenvolvimento das atividades. Está fragmentado em segmentos como: Home; Apresentação do projeto; Cartas e imagens das cidades brasileiras; Mosaicos; Cursos; Sala de aula; Eventos; Apostilas; Downloads; Links; Notícias; Tutoriais; EducARTE e Atlas. A figura 1 ilustra o mosaico produzido pelo programa EducaSere.

O Mosaico do Vale do Paraíba, Litoral Norte e Serra da Mantiqueira, possui a escala 1:350.00 e foi gerado a partir de duas imagens LANDSAT/TM, passagens de 26 de julho e 20 de agosto de 1997, órbita 21, pontos 75 e 76, publicado em parceria com o Jornal Vale Paraibano de São José dos Campos, na edição do dia 21 de agosto de 1999, em toda a região abrangida pelo Jornal Vale paraibano. Mais tarde foi impresso na forma de poster e amplamente distribuído na Bienal de Arquitetura realizada em São Paulo, neste mesmo ano, e para toda a rede de ensino de São José dos Campos. As figuras 2 e 3 representam exemplos de Carta Imagem que também são confeccionadas através do site do projeto Educa SeRe. 


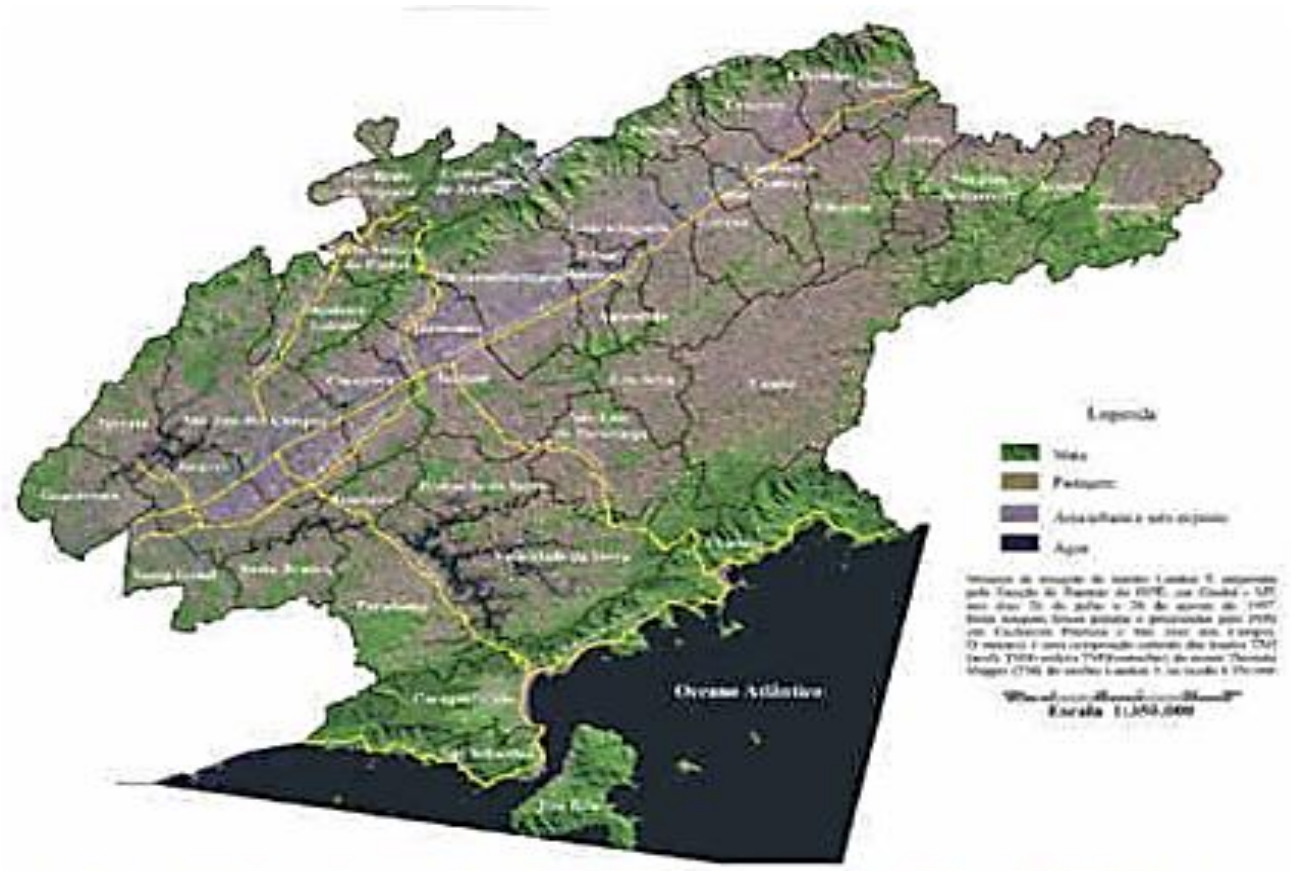

Mosaico do Vale do Paraíba, Litoral Norte e Serra da Mantiqueira

Figura 1. Mosaico do Vale do Paraíba, produzido pelo programa EducaSere. Fonte: http://www3.inpe.br/unidades/cep/atividadescep/educasere/index.htm. Acesso em 12/12/2020.

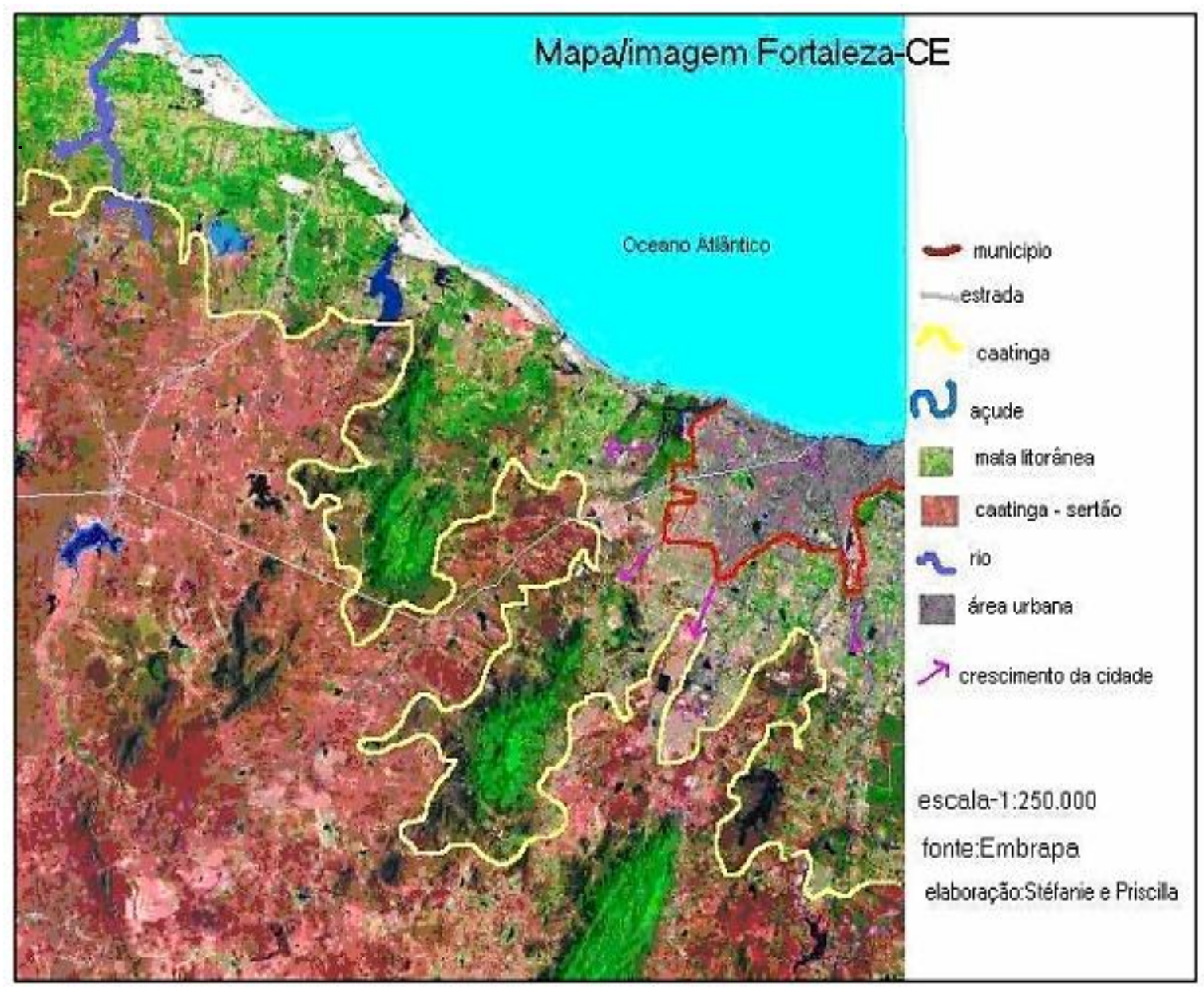

Figura 2. Carta imagem de Fortaleza/CE. Fonte: Sausen e Coelho [22]. 
De acordo com Sausen e Coelho [22] entende-se por carta "imagem referenciada a partir de pontos identificáveis e com coordenadas conhecidas, superposta por reticulado da projeção, podendo conter simbologia e toponímia." A partir desta definição é possível infe rir que o georreferenciamento de uma imagen, expresso na forma de coordenadas geográficas, já define uma carta imagem. Indicações adicionais poderão compor as variaveis qualitativas que venham servir para colocar em evidências informações que se julguem necessárias. A indicação de nomes de lugares também podem servir como auxiliares na localização de elementos através de sua posição em relação ás coordenadas.

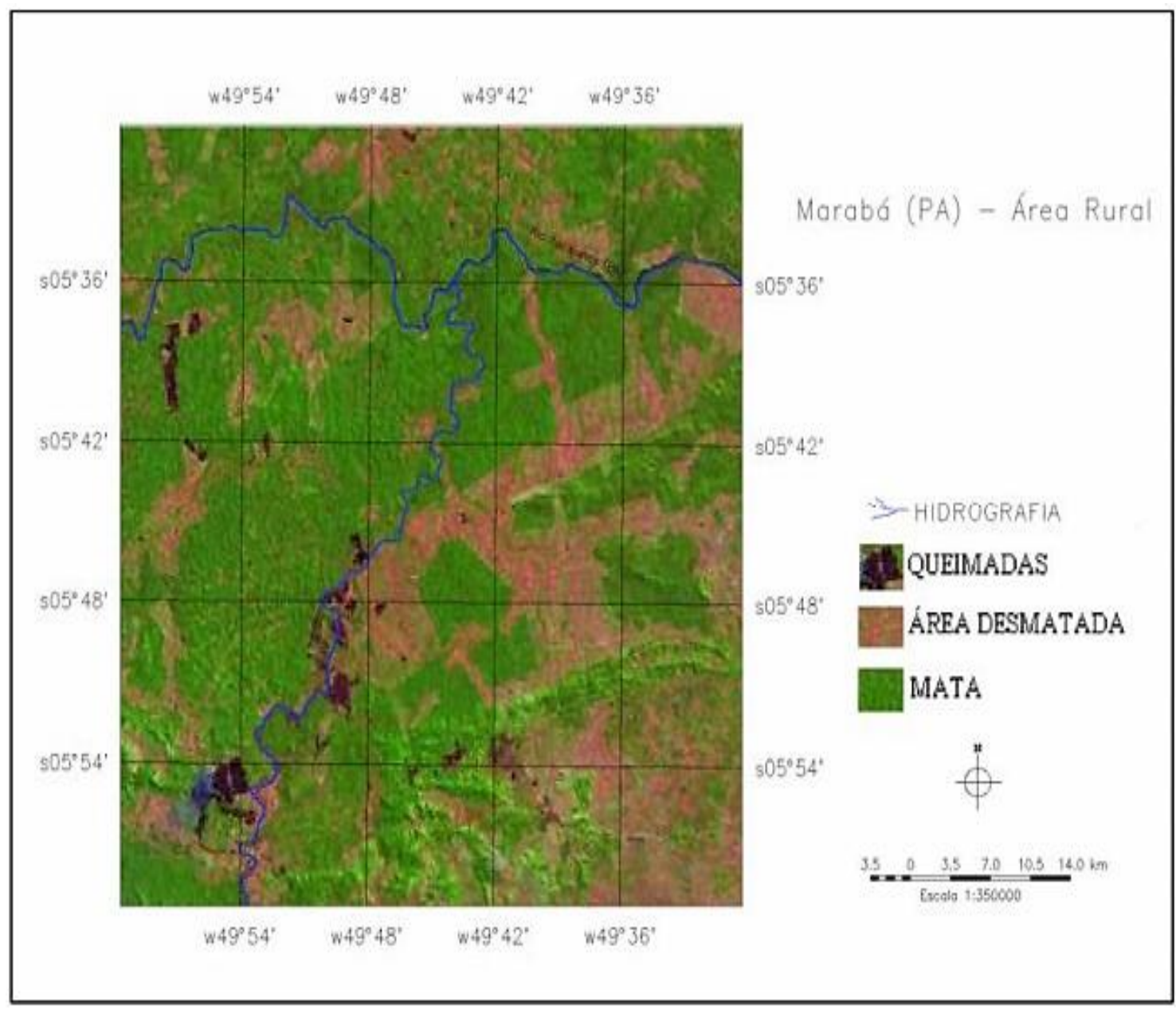

Figura 3. Carta Imagem Região Amazônica Fonte: Sausen e Coelho [22].

Na carta imagem da figura 3 é possível observar detalhes da Região Amazônica, tais como desmatamento devido a expansão agropecuária e as manchas escuras denunciando as queimadas da região. Estas são amostras das ferramentas e possibilidades que o projeto apresenta. Se possível for, esta atividade deve ser realizada no laboratório de informática da escola. Este projeto iniciou em 1998, e as primeiras cartas foram apresentadas no IX Simpósio Brasileiro de Sensoriamento Remoto, realizado em Santos, SP, em setembro de 1998. Foram feitas 3 mil cópias, em parceria com a SELPER e distribuídas durante o Simpósio e posteriormente para todos os interessados em vários estados brasileiros e para o exterior.

\subsection{Estudo do lugar}

Esta atividade de ação metodológica está adaptada de Santos e Filho [23]. Nela é proposta uma sequência didática para o estudo da "categoria lugar", onde o professor 
de geografia pode inicialmente trabalhar com mapas mentais, conforme ilustrado na figura 4, e percepção ambiental por meio dos desenhos. Com eles é possível compreender como os alunos se enxergam no espaço geográfico e conseguem distinguir as rugosidades dos elementos que compõe o espaço geográfico. Possivelmente os alunos irão traçar o caminho de casa até a escola, destacando todos os elementos que encontrarem no caminho, como por exemplo igreja, supermercados, parques, árvores, moradias e, em alguns casos o relevo, entre outros varios elementos.

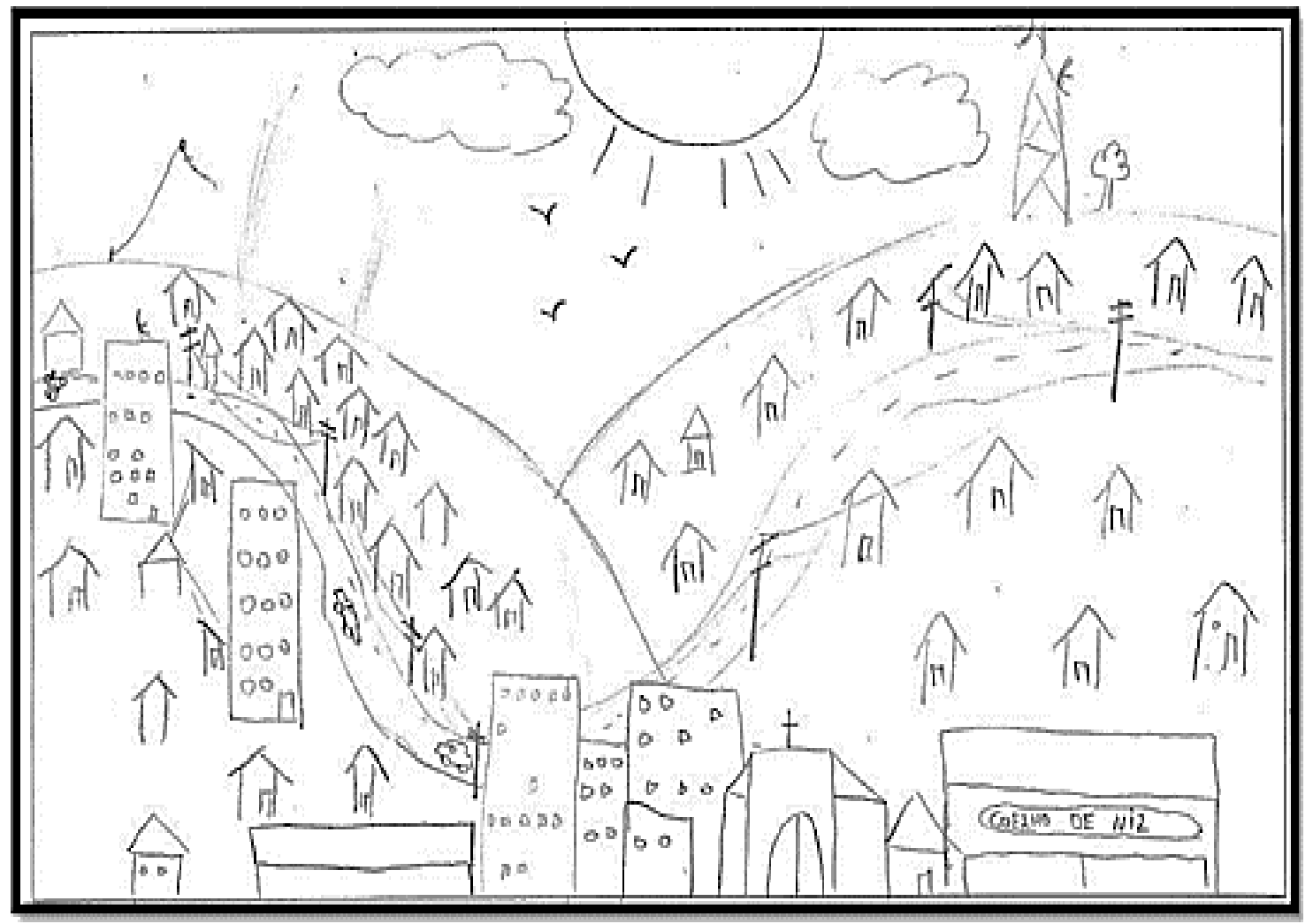

Figura 4. Exemplo de mapa mental comumente realizado pelos alunos. Fonte: Archela [24].

Após a finalização da atividade de execução dos desenhos, é sugerido que o professor avance para uma segunda etapa, na qual irá realizar a exposição de imagens de satélites da escola e das proximidades dela. Através desta prática será possivel que os alunos tenham uma boa ideia do espaço em que estão inseridos, pois os detalhes do local podem ser vistos como um todo e não separadamente. Assim, dessa forma, o espaço vivido torna-se mais fácilmente compreensível.

Conforme afirma Archela [24] os mapas mentais são imagens espaciais que as pessoas têm de lugares conhecidos, direta ou indiretamente. Portanto, essas representações espaciais mentais podem ser, por exemplo, do espaço vivido ou de acontecimentos sociais.

\subsection{Sensoriamento remoto no ensino de geomorfologia}

A presente ação metodológica está adaptada de Pereira e Silva [25]. Esta proposta de atividade está vinculada com o ensino de geomorfologia nas aulas de geografia na educação básica. Inicialmente sugere-se que o professor faça uma explanação acerca dos principais conceitos da geomorfología e feições do relevo, com o intuito dos 
educandos assimilarem a parte prática da atividade. A plataforma utilizada pode ser 0 Google Earth. A atividade deve ser executada no laboratório de informática da escola.

O professor pode inicialmente trabalhar com imagens de satélites exibindo as feições do relevo do municipio com objetivo de familiarização de interpretação da paisagem. Isso se constitui em uma maneira de aproximar a vida cotidiana dos alunos com a complexidade das formas do relevo. Após esta etapa, se pode explorar outras regiões do estado ou até mesmo de diversos lugares do país solicitando que façam comparações em relação as diferenças e/ou diferenças observadas no relevo dos diferentes lugares. Para finalizar a atividade, o professor pode também disponibilizar um roteiro de questões no intuito de contemplar o olhar do aluno, o grau de aceitação da atividade, e avaliar a aprendizagem. A sugestão é de que estas atividades sejam realizadas apartir do $5^{\circ}$ ano, conforme está indicado pela Base Nacional Comum Curricular- BNCC. O quadro 2 ilustra algumas sugestões dos possíveis questionamentos que podem ser aplicados.

Quadro 2. Sugestões de possíveis questões a serem trabalhadas.

Você já sabia o que é o Sensoriamento Remoto?

Antes da atividade você teve contato com o Google Earth?

De que forma você acha que as imagens de satélites contribuiram para a compreensão do conteúdo?

> Por que você considera importante estudar a geomorfologia por meio das imagens de satélites?

$>$ Gostou da atividade? Gostaria de que acontecesse com mais frequência?

\subsection{Metodologia com o uso de imagens de satélites}

Esta metodología está adaptada de Bonini [26]. Nela, o professor de geografia pode selecionar imagens de satélites do bairro onde a escola está localizada, uma vez que é um lugar que os alunos já conhecem e assim terão facilidade em desenvolver o trabalho. As imagens podem ser obtidas a partir do programa Google Earth, e, sugerese que elas sejam selecionadas em um intervalo de pelo menos dez anos.

Inicialmente o professor pode apresentar a atividade e sugerir aos alunos que realizem uma análise das imagens, anotem as observações e alterações na paisagem ao longo dos anos, indicando quais processos colaboraram para essas mudanças bem como quais contribuem efetivamente para a melhoria do ambiente em que vivem. Ao desenvolver esta atividade os alunos estarão sendo instigados a pensar de forma crítica em relação as mudanças que ocorreram ao longo dos anos e pensar em ações que podem ser desenvolvidas para o planejamento da ocupação do espaço. Desta forma, refletindo sobre a influência humana nas transformações da paisagem, os 
alunos percebem-se como integrantes, atores e agentes transformadores do espaço geográfico.

Através do desenvolvimento das atividades, os alunos serão estimulados a refletir sobre alguns tópicos como, por exemplo, degradação ambiental, mudanças na paisagem, desmatamento e invasão humana em áreas de vegetação. Os alunos podem anotar as modificações observadas nas imagens e como é uma atividade que pode ser facilmente desenvolvida na sala de aula, torna-se acessível a profesores e alunos e pode ser muito eficaz na aprendizagem.

\subsection{Metodologia vinculada a questões ambientais}

Esta metodología, adapatada de Vilhena et al. [27], sugere o estudo da ocupação desordenada em lugares inadequados para habitação humana. Essa inadequação se torna um local de área de risco para diversos eventos geomorfológicos. O risco não está associado apenas à prejuízos materiais, mas também danos sociais e ambientais, podendo ser clasificado em diferentes escalas e proporções. Neste sentido, este problema não é apenas de cunho ambiental, mas também está relacionado a geografia humana vinculado aos conceitos urbanos.

Através do estudo da ocupação desordenada em lugares inadequados para habitação humana, o professor de geografia consegue desenvolver, como estratégia de ensino, diversos conteúdos ambientais e humanos, instigando a criticidades dos alunos e, também, preparando-os para realizarem a leitura completa do espaço geográfico e suas transformações por meio da interpretação das imagens de satélites. Sugere-se então, que o professor pode definir a área de estudo e o local pode ser uma área considerada de risco. A partir da definição do local, pode-se selecionar registros aéreos do local em períodos diferentes. Recomenda-se o intervalo entre duas décadas para que as transformações na paisagem sejam bem visíveis.

Aconselha-se que o professor escolha um local onde existam fenômenos como, por exemplo, escorregamentos pois desta forma ele poderá abordar conteúdos como solos, rochas e vegetação. Estes eventos costumam ocorrer em terrenos inclinados, denominados de encostas das quais foram retiradas a cobertura vegetal original. Neste sentido, as imagens também podem auxiliar no ensino de climatología, pois no Brasil predomina um clima tropical, onde ocorrem grandes volumes pluviométricos com períodos de chuvas abundantes.

\section{Conclusão}

O presente estudo buscou realizar um levantamento de metodologias de possível aplicação pelo professor de geografia no nível de ensino básico, utilizando a técnica do sensoriamento remoto como recurso didático. Confirma-se a hipótese de que apesar das imagens de satélites e imagens aéreas serem cotidianamente utilizadas, estas já consolidaram seu espaço nos atlas, livros didáticos, filmes e mídias em geral. Entretanto, quando se refere ao ensino, o uso do sensoriamento remoto, como técnica, ainda é explorado de forma insuficiente como recurso didático.

Observa-se que as imagens aéreas colaboram no processo de ensino e aprendizagem, entretanto é imprescindível que os professores estejam capacitados e preparados para desenvolver um bom trabalho, utilizando-se como apoio, as geotecnologias. Neste sentido, torna-se necessário que haja investimentos em cursos de capacitação e formação continuada para os professores, voltados ao ensino das tecnologias. 
Compreende-se que existem diversas metodologias que garantem a participação ativa dos alunos no processo da construção do saber. Desta forma, os alunos não exercem o papel de receptores como sugere a tendência pedagógica tradicional que por muitos anos foi tida como a única e absoluta forma de ensinar. Ao longo das décadas os conceitos da educação foram evoluindo ancorados na forma de ensinar aprender e, hoje sabe-se que a educação construtivista, aliada à aprendizagem significativa é muito positiva na construção do saber.

A maneira de conduzir as aulas de geografia pode estar fundamentada como um momento de satisfação e qualidade na aprendizagem do aluno. Desta forma, os professores podem buscar novas estratégias para deixar as aulas dinâmicas, tornando a aprendizagem construtiva e, nesse sentido, o sensoriamento remoto, tem sido aliado no ensino da geografia nos mais diversos conteúdos e viabilizado o construtivismo em sala de aula. Os documentos como Base Nacional Comum Curricular (BNCC) e os Parâmetros Curriculares Nacionais (PCNs) destacam a importância da geografia apropriar-se das geotecnologias afim de obter resultados atrativos para os estudantes, tornando aprendizagem prazerosa.

\section{Referências}

[1] Carvalho V.M.S.G. de. Sensoriamento Remoto no ensino básico da geografia: definindo novas estratégias. Tese de Doutorado. Rio de Janeiro: Universidade Federal do Rio de Janeiro; 2006.

[2] Kramer G, Maass P.A, Filho W.P. O uso do Sensoriamento Remoto como recurso didático para o ensino da Geografia no sexto ano do Ensino Fundamental. Anais XIV Simpósio Brasileiro de Sensoriamento Remoto, Natal, Brasil, 25-30 abril 2009, INPE, p. 2429-2435. Disponível em:

$<$ http://marte.sid.inpe.br/col/dpi.inpe.br/sbsr\%4080/2008/11.17.18.35/doc/2429-

2435.pdf>. Acesso em: 12 de nov. 2020.

[3] BRASIL. Ministério da Educação. Base Nacional Comum Curricular: proposta preliminar. 2. ed. Brasília: MEC, 2016. Disponível em: $<$ http://portal.mec.gov.br/index.php?option=com_docman\&view=download\&alias=7823 1-anexo-texto-bncc-reexportado-pdf-1\&category_slug=dezembro-2017pdf\&Itemid=30192 > . Acesso em: 15 de nov. 2020.

[4] Masseto M.T. Mediação Pedagógica e Tecnologias de Informação e Comunicação. In: Moran J.M., Masetto M.T., Behrens M.A. (Org.). Novas tecnologias e mediação pedagógica. 21a Ed. Campinas (SP): Papirus, 2013.

[5] Lima J.V.de, Singo F., Canto Filho A., Müller T., Silva F. (Org.). Objetos de aprendizagem multimodais:

aplicações. Barcelona (Espanha): Editorial UOC, 2014.

projetos

[6] Tajra S.F. Informática na educação: novas ferramentas pedagógicas para o professor na atualidade. 9. ed., rev., atual. e ampl. São Paulo (SP): Érica, 2012.

[7] Fitz P.R. Geoprocessamento sem complicação - São Paulo, SP: Oficina de Textos, 2008.

[8] Mendonça R.A.M., Bernasconi P., Santos R., Scaranello M. Uso das Geotecnologias para Gestão Ambiental: Experiências na Amazônia Meridional 2011. Disponível em: https://www.icv.org.br/drop/wp-content/uploads/2013/08/uso-dasgeocnologias-para-gest\%C3\%A3o-ambiental.pdf. Acesso em: 18 de dez. 2020. 
[9] Freire P. Pedagogia da autonomia: saberes necessários à prática educativa. 8. Ed. São Paulo: Paz e Terra, 1996.

[10] Pontuschka N.N., Paganelli T.I., Cacete N.H. Para ensinar e aprender Geografia. 3 ${ }^{\text {a }}$ ed. São Paulo: Cortez, 2009. Disponível em: <http://www.educadores.diaadia.pr.gov.br/arquivos/File/deb_nre/ensinar_aprender_ge ografia.pdf>. Acesso em: 22 de dez. 2020.

[11] Cavalcanti L. de S. Geografia e prática de ensino. Goiânia: Alternativa, 2002. Disponível em: <http://www.apegeo.com.br/encontro2016/wpcontent/uploads/2016/06/ANAIS_IV_EREG_2014.pdf>. Acesso em 22 de dez. 2020.

[12] BRASIL. Ministério da Educação. Secretaria de Educação Média e Tecnológica. Parâmetros curriculares nacionais. Brasília, 2007. Disponível em: $<$ http://portal.mec.gov.br/setec/arquivos/pdf/BasesLegais.pdf>. Acesso em: 25 de dez. 2020.

[13] Santos M. A Natureza do Espaço: Técnica e Tempo, Razão e Emoção. 4. ed. 2. reimpr. - São Paulo: Editora da Universidade de São Paulo, 2006.

[14] Oliveira de M.C. de S.R.M. Os globos virtuais no ensino da Geografia: - a noção de espaço em alunos do $3^{\circ}$ Ciclo do Ensino Básico. Dissertação de mestrado. Universidade de Aveiro. Portugal; 2010.

[15] Ferreira D.M, Cunha F.S. da. Modelagem digital no ensino de geografia. Revista Homem, Espaço e Tempo, out, 2010.

[16] Facincani C. A utilização do Google Earth na disciplina de Geografia. Monografia do Curso de Especialização em Informática na Educação - Modalidade a Distância Instituto de Computação da Universidade Federal de Mato Grosso. 2011. Disponível em: <https://silo.tips/download/a-utilizaao-do-google-earth-na-disciplina-de-geografia>. Acesso em: 02 de jan. 2021.

[17] Florenzano T.G., Imagens de satélites para os estudos ambientais. São Paulo: Oficina de 2002.2 Disponível em: <https://edisciplinas.usp.br/pluginfile.php/5692586/mod_resource/content/2/Imagens\% 20de $\% 20$ sate $\%$ CC $\% 81$ lite $\% 20$ para\%20estudos\%20ambientais.pdf>. Acesso em: 05 de jan. 2021.

[18] Santos V.M.N. Escola, cidadania e novas tecnologias: o Sensoriamento Remoto no ensino. São Paulo: Ed. Paulinas, 2002.

[19] Vilhena D. da C., Tavares Júnior S.S., Besserra Neta L.C. O Sensoriamento Remoto como recurso didático no ensino de Geografia. Revista Geonorte, Edição Especial 1: Geografia Física 2012; 3(5): 1624-1635. Disponível em: $<$ https://www.periodicos.ufam.edu.br/index.php/revistageonorte/article/view/2218/2093 >. Acesso em: 10 de jan. 2021.

[20] Santos V.M.N. O uso escolar das imagens de satélites: socialização da ciência e tecnologia espacial. In: Penteado H.D. Pedagogia da comunicação: teoria e prática. São Paulo: Cortez. 1998. 
[21] Borges G.M. O uso do sensoriamento remoto como recurso didático nas aulas de geografia do ensino médio: desafios e possibilidades para uma ação pedagógica. Dissertação de mestrado. Universidade Federal de Pernambuco; 2015.

[22] Sausen T. M, Coelho O.G.W. Projeto Educa SeRe - ensino de geografia no ensino fundamental e médio usando Sensoriamento Remoto. 4ª Jornada de Educação em Sensoriamento Remoto no Âmbito do Mercosul - São Leopoldo, Rio Grande do Sul. 2004.

Disponível

em: <http://www3.inpe.br/unidades/cep/atividadescep/jornada/programa/t-5_trab_32.pdf>. Acesso em: 23 de jan. 2021.

[23] Santos F., Filho W. O uso de imagens de satélite como recurso didático para o estudo da categoria lugar. Geo UERJ. 2010. Disponível em: <http://www.epublicacoes.uerj.br/index.php/geouerj/article/view/1490>. Acesso em: 25 de jan. 2021.

[24] Archela R.S., Gratão L.H.B., Trostdorf M.A.S. O lugar dos mapas mentais na representação do lugar. Geografia Londrina Londrina 2004; 13(1): 127-141. http://dx.doi.org/10.5433/2447-1747.2004v13n1p127.

[25] Pereira J.S.E., Silva R.G.S. O ensino de geomorfologia na educação básica a partir do cotidiano do aluno e o uso de ferramentas digitais como recurso didático. Revista de Ensino de Geografia, Uberlândia 2012; 3(4): 69-79. Disponível em: <http://www.revistaensinogeografia.ig.ufu.br/N.4/art5v3n4.pdf>. Acesso em: 27 de jan. 2021.

[26] Bonini A.M. Ensino de geografia: utilização de recursos computacionais (Google Earth) no ensino médio. 2009. 178 f.: 2 DVDs. Tese de Doutorado. São Paulo: Universidade Estadual Paulista, Instituto de Geociências e Ciências Exatas; 2009.

[27] Vilhena D. da C., Tavares Júnior S.S., Besserra Neta L.C. O Sensoriamento Remoto como recurso didático no ensino de Geografia. Anais XVI Simpósio Brasileiro de Sensoriamento Remoto - SBSR, Foz do Iguaçu, PR, Brasil, 13 a 18 de abril de 2013.

\section{Autores}

Cibele Stefanno Saldanha*, Marcia Elena de Mello Cardias, Mauro Kumpfer Werlang

Programa de Pós Graduação em Geografia, Universidade Federal de Santa Maria/UFSM, Av. Roraima no 1000, Santa Maria - RS, Brasil.

* Autor para correspondência: cibele2012stefanno@gmail.com 